\title{
FAMLF is a target of miR-181b in Burkitt lymphoma
}

\author{
J.G. Li ${ }^{1}$, Y. Ding ${ }^{2}$, Y.M. Huang ${ }^{2}$, W.L. Chen ${ }^{2}$, L.L. Pan ${ }^{1}$, Y. Li ${ }^{1}$, X.L. Chen ${ }^{2}$, Y. Chen ${ }^{2}$, \\ S.Y. Wang ${ }^{1}$ and X.N. $\mathrm{Wu}^{3}$ \\ ${ }^{1}$ Department of Hematology, Fujian Institute of Hematology, Fujian Medical University Union Hospital, Fuzhou, China \\ ${ }^{2}$ Union Clinical Medical College, Fujian Medical University, Fuzhou, China \\ ${ }^{3}$ School of Public Health, Fujian Medical University, Fuzhou, China
}

\begin{abstract}
Burkitt lymphoma $(\mathrm{BL})$ is a highly malignant non-Hodgkin's lymphoma that is closely related to the abnormal expression of genes. Familial acute myelogenous leukemia related factor (FAMLF; GenBank accession No. EF413001.1) is a novel gene that was cloned by our research group, and miR-181b is located in the intron of the FAMLF gene. To verify the role of miR-181b and FAMLF in BL, RNAhybrid software was used to predict target site of miR-181b on FAMLF and real-time quantitative PCR (RQ$\mathrm{PCR}$ ) was used to detect expression of miR-181b and FAMLF in BL patients, Raji cells and unaffected individuals. miR-181b was then transfected into Raji and CA46 cell lines and FAMLF expression was examined by RQ-PCR and western blotting. Further, Raji cells viability and proliferation were detected by MTT and clone formation, and Raji cell cycle and apoptosis were detected by flow cytometry. The results showed that miR-181b can bind to bases 21-42 of the FAMLF $5^{\prime}$ untranslated region (UTR), FAMLF was highly expressed and miR-181b was lowly expressed in BL patients compared with unaffected individuals. FAMLF expression was significantly and inversely correlated to miR-181b expression, and miR-181b negatively regulated $F A M L F$ at posttranscriptional and translational levels. A dual-luciferase reporter gene assay identified that the $5^{\prime}$ UTR of $F A M L F$ mRNA contained putative binding sites for miR-181b. Down-regulation of $F A M L F$ by miR-181b arrested cell cycle, inhibited cell viability and proliferation in a BL cell line model. Our findings explain a new mechanism of BL pathogenesis and may also have implications in the therapy of FAMLF-overexpressing BL.
\end{abstract}

Key words: Burkitt lymphoma; FAMLF; miR-181b; Gene expression; RQ-PCR

\section{Introduction}

Burkitt lymphoma (BL) is a highly aggressive nonHodgkin's B-cell lymphoma and affects children and adolescents more commonly. Patients often present with a large tumor, a high tumor burden and mortality due to the short doubling time of the tumor (1). Studies have shown that Epstein-Barr virus (EBV) infection and eight chromosome $M Y C$ oncogene translocations were involved in the pathogenesis of BL. Activation of the MYC gene may promote cell proliferation and malignant transformation, and lead to the occurrence of tumors (2). However, EBV infection and $M Y C$ oncogene translocation were not detected in some $\mathrm{BL}$ cases, indicating that the complete molecular mechanisms of the pathogenesis of BL have not been fully elucidated.

Familial acute myelogenous leukemia related factor (FAMLF; GenBank accession No. EF413001.1) is a novel leukemia-associated gene that was cloned and identified by a series of molecular biology techniques from a large family with a high incidence of leukemia in Fujian, China. The FAMLF gene is located on human chromosome 1q32.1; its full-length cDNA is $2313 \mathrm{bp}$ and encodes an 82-amino acid polypeptide (protein accession no. ABN58747) (3-5). Studies have shown that FAMLF was highly expressed in acute myeloid leukemia and BL patients, NB4 acute promyelocytic leukemia cells, U937 macrophage-like cells, K562 myeloid leukemia cells, U266 myeloma cells, HL60 promyelocytic cells, CA46 lymphoma cells, and especially in Raji BL cells, while low expression was observed in unaffected individuals. FAMLF may be involved in hematopoietic neoplasms by promoting cell proliferation and preventing cell differentiation $(6,7)$.

Micro RNAa (miRNAs) are small non-coding RNA molecules that contain approximately 19-24 nucleotides that down-regulate gene expression, primarily by basepairing to the $3^{\prime}$ untranslated region (UTR) of target mRNAs (8). A previous study showed that miRNAs are widely involved in many pathophysiological processes and are associated with a variety of malignant tumors (9). Multiple miRNA expression and regulation abnormalities were also found in $\mathrm{BL}(10-13)$, indicating that miRNAs are closely associated with the pathogenesis of BL. 
miR-181b is located in the intron of the FAMLF gene, making FAMLF the host gene of miR-181b. Previous studies have shown that intronic miRNAs and host genes are closely related and that intronic miRNAs could negatively regulate expression of host genes (14-17). The aim of this study was to evaluate the expressions of miR-181b and FAMLF in BL and in Raji BL cells.

\section{Material and Methods}

\section{Patient samples}

The study was approved by Fujian Medical University Ethics Committee. Forty-five samples were obtained with written informed consent from 30 patients diagnosed with $\mathrm{BL}$ at Fujian Institute of Hematology and from 5 unaffected individuals. Samples were obtained also from $2 \mathrm{BL}$ cell lines. Of the 30 patients, 19 were male and 11 were female, the median age was 13 years (range 1-42 years), 6 of the 45 samples were from patients who were in remission, and 2 were from patients with recurrent disease. Clinical characteristics of the cohort are listed in Table 1. Expressions of miR-181b and FAMLF were detected in a paired manner in each specimen.

\section{Real-time quantitative PCR (RQ-PCR) for FAMLF}

Total RNA was extracted from bone marrow mononuclear cells or ground tumor tissue by using TRIzol Reagent (Invitrogen, USA), first-strand cDNA was synthesized using a RevertAid TM First Strand cDNA Synthesis Kit (Fermentas, Canada), and the following specific primers were used to amplify FAMLF by RQ-PCR: forward primer, $5^{\prime}$-ACCGTT TTGAAATTAGATCC-3'; reverse primer, 5'-CGATTGAACT AAAAGA AATGAC-3'. $\beta$-actin was used as the internal control gene: forward primer, 5'-AGTGTGACGTGGAC
ATCCGCAAAG-3'; reverse primer, 5'-ATCCACATCTGC TGGAAGGTGGAC-3'. All primers were synthesized by Shanghai Invitrogen Biotechnology Co. Ltd. (China). RQPCR was performed on a 7500-thermal cycler (ABI, USA) using FastStart Universal SYBR Green Master Mix (Roche, USA) with the following program: $50^{\circ} \mathrm{C}$ for $2 \mathrm{~min}$ and $95^{\circ} \mathrm{C}$ for $10 \mathrm{~min}$, followed by 40 cycles of $95^{\circ} \mathrm{C}$ for $15 \mathrm{~s}$ and $58^{\circ} \mathrm{C}$ for $1 \mathrm{~min}$. All samples were run in triplicate, and the $2^{-\Delta \mathrm{Ct}}\left({ }^{\Delta} \mathrm{Ct}=\mathrm{CT}_{F A M L F}-\mathrm{CT}_{\beta \text {-actin }}\right)$ method was used to estimate the relative expression level of the FAMLF gene.

\section{RQ-PCR for miR-181b}

MicroRNA was extracted from bone marrow mononuclear cells or ground tumor tissue by using a miRNeasy Mini Kit (QIAGEN, Germany). U6 was used as the internal control for miRNA and reverse transcription-specific primers with stem loop structures were designed according to Chen et al. (18): miR-181b, 5'-GTCGTATCCAGTGCAGG GTCCGAGGTATTCGCACTGGATACGACAACCCACCG-3'; U6, 5'-GTCGTATCCAGTGCAGGGTCCGAGGTATTCGC ACTGGATACGACAAAAATATG-3'. Reverse transcription was performed on a 2720 thermal cycler (ABI) using a TaqMan microRNA Reverse Transcription Kit (ABI). The following specific primers were used to amplify miR-181b and U6: miR-181b forward primer, 5'-AACATTCATTGCT GTCGGTGGGT-3'; U6 forward primer, 5'-GCGCGTCGT GAAGCGTTC-3'; universal reverse primer, 5'-GTGCAGG GTCCGAGGT-3'. RQ-PCR was performed on a 7500thermal cycler (ABI) using the TaqMan microRNA Assay $(\mathrm{ABI})$ with the following program: $50^{\circ} \mathrm{C}$ for $2 \mathrm{~min}$ and $95^{\circ} \mathrm{C}$ for $10 \mathrm{~min}$, followed by 40 cycles of $95^{\circ} \mathrm{C}$ for $15 \mathrm{~s}$ and $60^{\circ} \mathrm{C}$ for $1 \mathrm{~min}$. All samples were run in triplicate, and the $2^{-\Delta \mathrm{Ct}}\left(\Delta \mathrm{Ct}=\mathrm{CT}_{\mathrm{miR}-181 \mathrm{~b}}-\mathrm{CT}_{\mathrm{U}}\right)$ method was used to estimate the relative expression level of miR-181b.

Table 1. Clinical characteristics of unaffected individuals (controls) and Burkitt lymphoma (BL) patients.

\begin{tabular}{|c|c|c|c|c|}
\hline & Controls $(n=5)$ & de novo $(\mathrm{n}=30)$ & Remission $(n=6)$ & Relapse $(n=2)$ \\
\hline Age (years) & $27(14-40)$ & $13(1-42)$ & $17(5-38)$ & $(8,35)$ \\
\hline Male $(n, \%)$ & $3(60)$ & $19(63.3)$ & $4(66.7)$ & $1(50)$ \\
\hline Female $(n, \%)$ & $2(40)$ & $11(36.7)$ & $2(33.3)$ & $1(50)$ \\
\hline Organomegaly (n, \%) & 0 & $12(40.0)$ & 0 & $1(50)$ \\
\hline CNS involvement (n, \%) & 0 & $10(33.3)$ & 0 & $2(100)$ \\
\hline WBC count $\left(\times 10^{9} / \mathrm{L}\right)$ & $6.85(4.32-8.94)$ & $14.57(0.67-35.84)$ & $5.44(3.64-8.45)$ & $(2.3,25.8)$ \\
\hline Hemoglobin (g/dL) & $13.9(12.8-15.5)$ & $8.9(5.1-13.8)$ & $12.7(10.1-15.0)$ & $(7.2,10.1)$ \\
\hline Platelet count $\left(\times 10^{9} / \mathrm{L}\right)$ & $228(129-311)$ & $86(12-355)$ & $189(81-274)$ & $(70,85)$ \\
\hline $\mathrm{EBV}+(\mathrm{n}, \%)$ & 0 & $8(26.7)$ & 0 & $1(50)$ \\
\hline Chromosome translocation (n, \%) & 0 & $23(76.7)$ & $1(16.7)$ & $2(100)$ \\
\hline \multicolumn{5}{|l|}{ Specimen source (n, \%) } \\
\hline BMMC & $5(100)$ & $26(86.7)$ & $6(100)$ & $2(100)$ \\
\hline Tumor biopsy tissue & 0 & 4 (13.3) & 0 & 0 \\
\hline
\end{tabular}

Data are reported as medians and ranges, unless otherwise indicated. EBV: Epstein-Barr virus; CNS: central nervous system; WBC: white blood cell; BMMC: bone marrow mononuclear cell. 
miR-181b transfection and FAMLF assays

The Raji and CA46 cell lines were purchased from the cell library of the Chinese Academy of Medical Sciences. miR-181b mimics and miR-181b negative controls (NC) were synthesized by Guangzhou Ribobio Co. Ltd. (China). After recovery, cells were cultured in RPMI-1640 medium containing $10 \%$ fetal bovine serum (Biosera, France) at $37^{\circ} \mathrm{C}$ and $5 \% \mathrm{CO}_{2}$ with maximum humidity. The experiments were divided into three groups: the blank control group (group Raji and group CA46), the negative control group transfected with miR-181b NC (group Raji/NC and group CA46/NC) and the experimental group transfected with miR-181b mimics (group Raji/miR-181b and group CA46/miR-181b). Two independent experiments were performed and three biological replicates were performed for each experiment.

Raji and CA46 cells were seeded in 24-well plates. miR-181b mimics (30 pmol) or miR-181b NC (30 pmol) in $50 \mu \mathrm{L}$ of medium were mixed with $2 \mu \mathrm{L}$ of Lipofectamine 2000 (Invitrogen, USA) transfection reagent dissolved in $50 \mu \mathrm{L}$ of the same medium and allowed to stand at room temperature for $20 \mathrm{~min}$. The resulting $100-\mu \mathrm{L}$ transfection solutions were then added to each well containing $400 \mu \mathrm{L}$ of medium. After being incubated for $5 \mathrm{~h}$, miRNA was extracted and RQ-PCR was performed to detect the miR$181 \mathrm{~b}$ transfection efficiency as described above.

At $24 \mathrm{~h}$ after transfection, total RNA was extracted, and $\mathrm{RQ}-\mathrm{PCR}$ was performed to detect the expression of FAMLF at the mRNA level as described above. Total protein was extracted using a ProteoPrep Total Extraction Sample Kit (Sigma, USA), and the level of FAMLF protein was confirmed with a monoclonal anti-FAMLF antibody (Clone No. 269.3, Abmart, USA) according to standard procedures for western blotting. Normalization was performed using a monoclonal anti-actin antibody (Clone No. AC-16, Abmart), and the band intensity was quantified with the Doc Gel 2000 imaging analysis system (Bio-Rad, USA).

\section{Dual-luciferase reporter gene assays}

Wild-type and mutated $5^{\prime}$ UTRs of the FAMLF gene were, respectively, amplified by using the following primers incorporating the Sacl and Xbal restriction sites: FAMLF $5^{\prime}$ UTR forward primer, 5'-GAGCTCAGAACTGCAGATAGTA CAGC-3'; FAMLF 5' UTR reverse primer, 5'-TCTAGAT AAAAAATGGACTAGTGGACTG G-3'; mutated FAMLF $5^{\prime}$ UTR forward primer, 5'-GAGCTCTAGACCATCACCATC GACTGTCTGAGCACA-3'; mutated FAMLF 5' UTR reverse primer, 5'-TCTAGATA AAAAATGGACTAGTGGACTGG-3'. The wild type and mutated FAMLF $5^{\prime}$ UTR sequences were individually cloned upstream of the Renilla luciferase (hR/uc) gene in the dual-luciferase reporter gene vector pmiR-RB-Report ${ }^{\mathrm{TM}}$ (Ribobio, China) to construct the wild-type recombinant plasmid vector pmiR-RB-Report ${ }^{\mathrm{TM}} /$ FAMLF-5' UTR-WT (FAMLF-WT) and mutated recombinant plasmid vector pmiR-RB- Report ${ }^{\mathrm{TM}} / F A M L F-5^{\prime}$ UTRMT (FAMLF-MT). Wild-type and mutated inserts were confirmed by sequencing. The 293T cells were co-transfected in 24-well plates with $2 \mu \mathrm{g}$ recombinant plasmid vectors and $30 \mathrm{pmol}$ miR-181b using $2-\mu \mathrm{L}$ lipofectamine 2000 (Invitrogen, USA) according to the manufacturer's protocol. After a 48-h incubation, hRluc activity was detected by chemiluminescence and using the DualLuciferase Reporter Assay System (Promega, USA). Normalization was performed using the Firefly luciferase (hluc) gene. Two independent experiments were performed and three biological replicates were performed for each experiment.

\section{Cell viability and cell cycle assays}

After being transfected with miR-181b mimics or miR$181 \mathrm{~b} \mathrm{NC}$, cells were collected from culture and seeded in 96-well assay plates with three replicates. After being incubated for 0, 24, 48 and 72 h, 3-(4, 5-dimethylthiazol-2yl)-2, 5- diphenyltetrazolium bromide (MTT) (Sigma, USA) was added, and the cells were incubated at $37^{\circ} \mathrm{C}$ for $4 \mathrm{~h}$ followed by the addition of dimethyl sulfoxide (Sigma) to dissolve the formazan crystals. Absorbance was read at $570 \mathrm{~nm}$. Two independent experiments were performed.

For cell cycle analysis, the cells were seeded on 96well assay plates with three replicates. The transfected Raji cells were incubated for 0,24 and $48 \mathrm{~h}$, followed by the addition of propidium iodide (Sigma), and the cells were incubated at $4^{\circ} \mathrm{C}$ for $30 \mathrm{~min}$. The DNA content was detected by FC-50 flow cytometry (Beckman Coulter, USA) and cell cycle analysis was performed. Two independent experiments were performed.

\section{Cell proliferation and cell apoptosis assays}

The effects of miR-181b on the proliferation of Raji cells was analyzed by the clonogenic assay. Briefly, cells were collected from culture and seeded in 10-cm culture dishes at density of $10^{4}$ cells per dish with 6 replicates. Cells were incubated for 1 week at $37^{\circ} \mathrm{C}$ with $5 \% \mathrm{CO}_{2}$ until the cells in control dishes have formed visual colonies that were of a substantially good size. At the end of incubation period, the numbers of cell colonies (greater than 50 cells) were counted by light microscopy.

Apoptosis assays were performed according to the introduction in Annexin V-FITC Apoptosis Detection Kit (Sigma) as follows: after the transfected Raji cells were incubated for $0,24,48$ and $72 \mathrm{~h}$, the cells were harvested and washed with pre-chilled phosphate buffered saline (PBS) twice. A total of $10^{6}$ Raji cells were stained with FITC-labeled Annexin $\mathrm{V}$ and propidium iodide. The stained cells were analyzed by FC-50 flow cytometry (Beckman Coulter) for apoptosis assay.

\section{Statistical analysis}

The statistical software SPSS19.0 (USA) was used to draw a scatter diagram of the expression of miR-181b and FAMLF and to analyze their correlation. For cell viability, cell cycle, cell proliferation and cell apoptosis assays, data 
are reported as means $\pm S D$. Analysis of variance (ANOVA) and group q-tests were performed and $P<0.05$ was considered to be statistically significant.

\section{Results}

miR-181b expression was significantly inversely correlated to FAMLF expression in BL patients

miR-181b target site prediction for FAMLF was performed using the RNAhybrid program (http://bibiserv.techfak. uni-bielefeld.de/rnahybrid/) (19). We found that miR-181b can bind to bases 21-42 of the FAMLF $5^{\prime}$ UTR in an incomplete complementary manner (Figure 1). To evaluate this putative interaction, we first detected the expression levels of miR-181b and FAMLF and examined the correlation of the expression in $\mathrm{BL}$ patients, Raji BL cells and unaffected individuals. We found that miR-181b was little expressed and $F A M L F$ was highly expressed in $\mathrm{BL}$ patients and Raji $\mathrm{BL}$ cells, but miR-181b was highly expressed and FAMLF was little expressed in remission patients and unaffected individuals (Figure $2 \mathrm{~A}$ and $\mathrm{B}$ ). The expression of FAMLF was significantly inversely correlated to the expression of miR$181 \mathrm{~b}$, with the coefficient of correlation in the full set of 45 samples being -0.95 with $\mathrm{P}<0.01$ (Figure $2 \mathrm{C}$ ).

\section{miR-181b down-regulated the expression of} the $F A M L F$ gene at posttranscriptional and translational levels

To investigate the effects of miR-181b on FAMLF expression, we selected Raji and CA46 BL cells, which express high levels of $F A M L F$ and low levels of miR-181b. Synthesized miR-181b mimics were respectively transfected into Raji and CA46 cells and transfection efficiency was detected. We found that miR-181b expression was significantly increased in Raji cells (Figure 3A) and CA46 cells (Figure $4 A$ ) after transfection. Next, the expression of
FAMLF was detected at both the MRNA and protein levels. We found that $F A M L F$ mRNA was reduced in Raji cells (Figure $3 B$ ) and CA46 cells (Figure 4B) transfected with miR-181b, and that $F A M L F$ protein was reduced more compared with FAMLF mRNA (Figures $3 \mathrm{C}$ and $4 \mathrm{C}$ ). These results showed that $\mathrm{miR}-181 \mathrm{~b}$ can down-regulate the expression of $F A M L F$ gene at both the mRNA and protein levels.

miR-181b directly interacted with the $5^{\prime}$ UTR of FAMLF by incomplete complementary base pairing

Unlike regulation by complete complementary base pairing in plants, miRNAs in mammals regulate the expression of target mRNAs mainly by incomplete complementary base pairing. In a dual-luciferase assay, the existence of an interaction between miR-181b and wild-type FAMLF mRNA should reduce $h R / u c$ gene activity, while mutated $F A M L F$ mRNA would not bind with miR-181b and therefore would not alter the activity of the reporter gene. The data presented in Figure 5 shows a significant suppression of $h R / u c$ gene activity in the FAMLF-WT/miR-181b group, but no changes in the control groups. This result indicated a direct effect of miR-181b on FAMLF.

\section{FAMLF down-regulation by miR-181b inhibited cell} viability and arrested cell cycle in Raji cells

The previous results have shown that miR-181b directly down-regulated the expression of $F A M L F$ in Raji cells. We next studied the effect of $F A M L F$ down-regulation by miR-181b on cell viability. MTT assays showed that cell viability was significantly decreased in the Raji/miR-181b group compared with control groups, with $\mathrm{P}<0.01$ (Figure 6). In addition, we also analyzed the cell cycle distributions after transfection for 0,24 and $48 \mathrm{~h}$ and found that the relative amount of cells in G0/G1 phase was increased (58.98-72.94\%) in the Raji/miR-181b group, whereas the
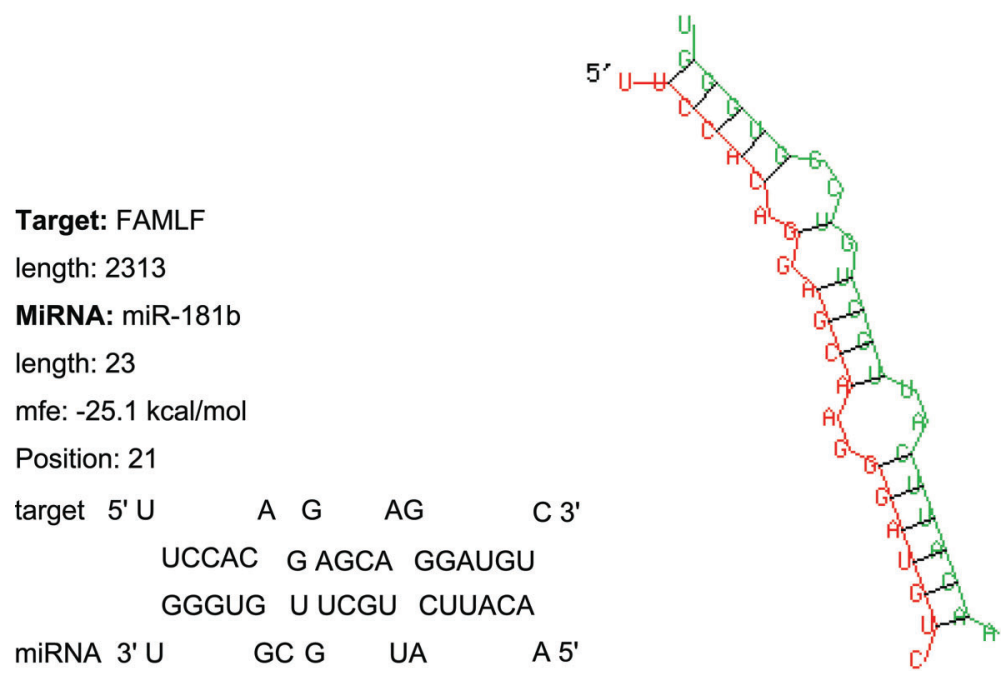

Figure 1. miR-181b target site prediction for FAMLF by the RNAhybrid program. miR-181b bound with bases 21-42 of the FAMLF $5^{\prime}$ untranslated region in an incomplete complementary manner. 

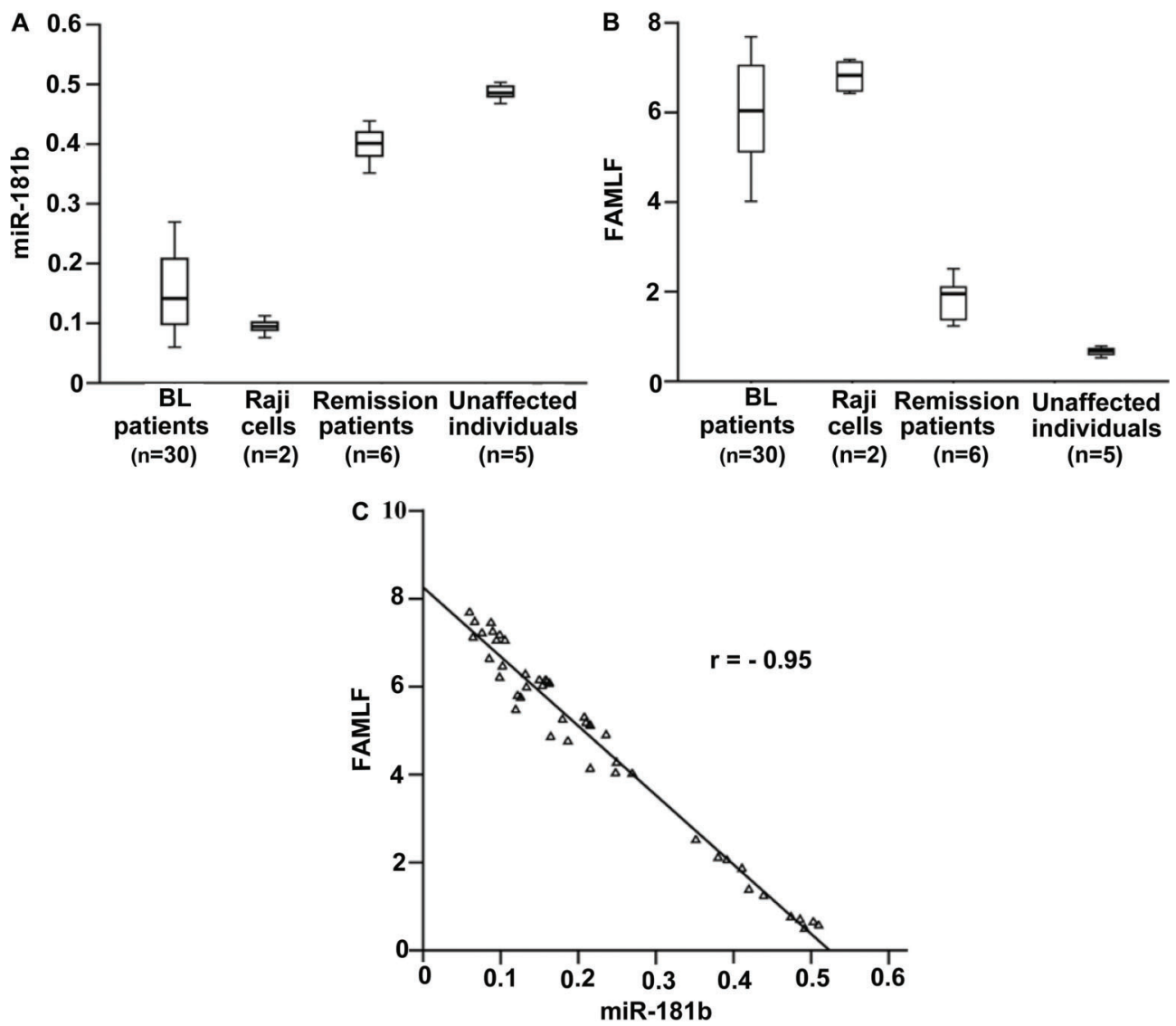

Figure 2. Expression of miR-181b and FAMLF in Burkitt lymphoma (BL) patients, Raji BL cells, remission patients and unaffected individuals. $A$, miR-181b was little expressed in BL patients and Raji BL cells, but highly expressed in remission patients and unaffected individuals. $B, F A M L F$ was highly expressed in $\mathrm{BL}$ patients and Raji $\mathrm{BL}$ cells, but little expressed in remission patients and unaffected individuals. C, FAMLF expression was inversely correlated with miR-181b expression. Data are reported as means $\pm S D$. $P<0.01$ (Pearson test).

percentage of cells in S and G2/M phase was reduced, with $\mathrm{P}<0.05$. The cell cycle distribution in the Raji/NC group had no obvious changes compared with the Raji group (Figure 7). These results showed that miR-181b inhibited Raji cells viability and arrested cell cycle by FAMLF downregulation.

\section{FAMLF down-regulation by miR-181b inhibited cell proliferation but had no effect on apoptosis in Raji cells}

The clonogenic assay is a commonly used way to evaluate cell proliferation ability. In this experiment, we observed a very strong decrease in colony-forming units in Raji/miR-181b group compared with control groups, with $\mathrm{P}<0.01$ (Figure 8). The results showed that FAMLF downregulation by miR-181b inhibited cell proliferation in Raji cells. However, we found no significant change in apoptosis rate in Raji/miR-181b group compared with control groups, with $\mathrm{P}>0.05$ (Figure 9).

\section{Discussion}

miR-181b is a member of the miR-181 family that is located on human chromosome 1q32. Recent studies have shown that miR-181b, as a small RNA molecule, was involved in cell differentiation and development as well as proliferation and apoptosis through the downregulation of target genes $(20,21)$. miR-181b plays a role in cancer enhancement by down-regulating anti-oncogenes. Tong et al. (22) reported that miR-181b promoted prostate cancer cell proliferation by regulating DAX-1 expression. However, in most instances, miR-181b plays a role of cancer suppressor by down-regulating oncogenes. Wang et al. (23) reported that miR-181b inhibited glioma cell proliferation by targeting cyclin B1. Pekarsky et al. (24) reported that the expression levels of Tcl 1 are inversely correlated with miR181 expression and that $\mathrm{Tcl} 1$ expression is regulated by miR-181 in chronic lymphocytic leukemia, but the role of miR-181b has not been described in BL. Our research 

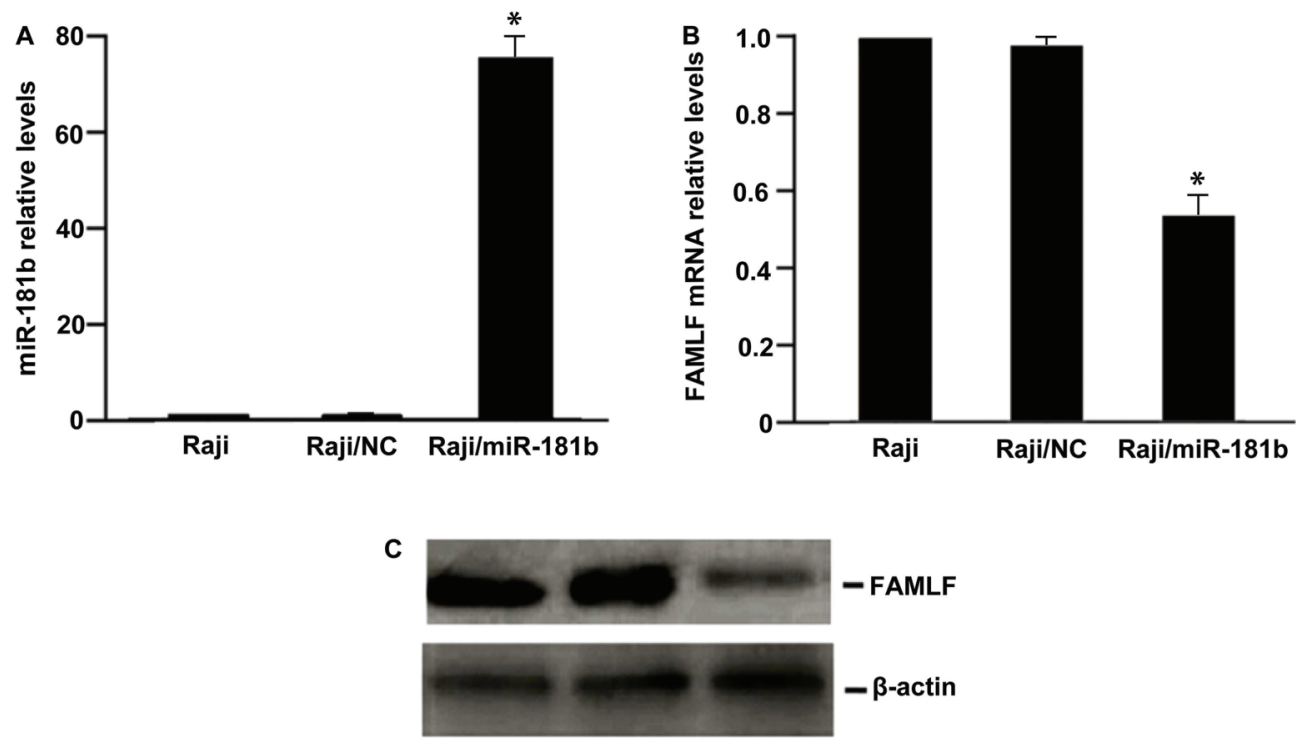

Raji Raji/NC Raji/miR-181b

Figure 3. Detection of miR-181b transfection efficiency and FAMLF expression in Raji cells. $A$, miR-181b expression was increased 75 times after transfection. $B, F A M L F$ mRNA expression was reduced by half after transfection. $C$, FAMLF protein was reduced by approximately $20 \%$ after transfection. Raji group was used as the control (NC) and was normalized. Data are reported as means \pm SD $(\mathrm{n}=6) .{ }^{*} \mathrm{P}<0.01$, Raji/miR-181b compared to Raji and Raji/NC (ANOVA).
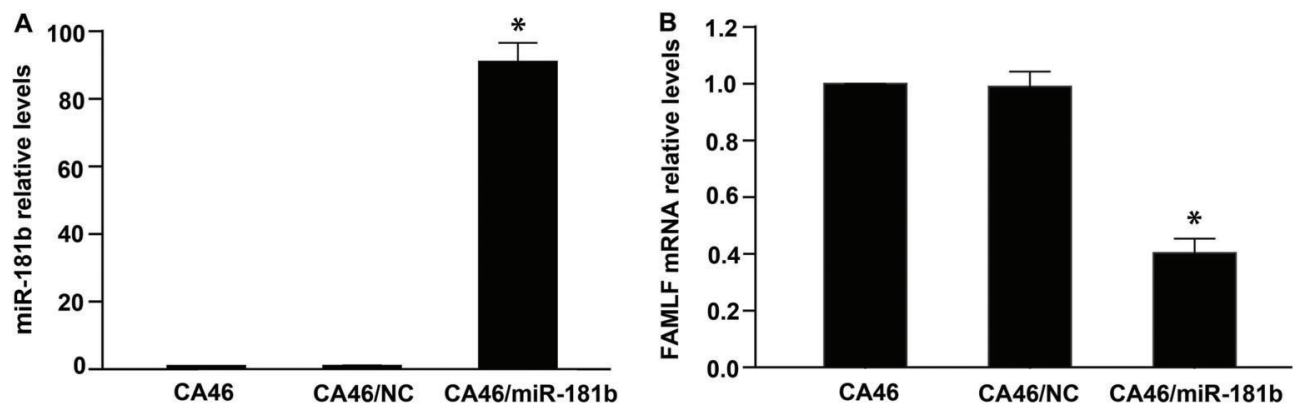

C

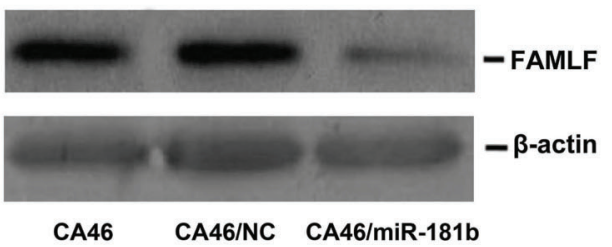

Figure 4. Detection of miR-181b transfection efficiency and FAMLF expression in CA46 cells. $A$, miR-181b expression was increased 91 times after transfection. $B, F A M L F$ mRNA expression was reduced by $40 \%$ after transfection. $C$, FAMLF protein expression was reduced by $14 \%$ after transfection. CA46 group was used as a control (NC) and was normalized. Data are reported as means \pm SD $(n=6) .{ }^{*} \mathrm{P}<0.01, \mathrm{CA} 46 / \mathrm{miR}-181 \mathrm{~b}$ compared to CA46 and CA46/NC (ANOVA).

showed that miR-181b was down-regulated and might act as a cancer suppressor in BL.

The FAMLF gene is a novel gene cloned from leukemia patients that is not only highly expressed in leukemia but also in other tumors, especially in BL, indicating its widespread cancer promoting activity. However, the mechanism by which FAMLF gene is highly expressed and how is it regulated in tumors is still unclear. Recent studies have indicated that more than $30 \%$ of the protein coding genes may be the target genes of miRNAs (25). 
About half of the known miRNA genes are located within introns of host genes and an intronic miRNA might

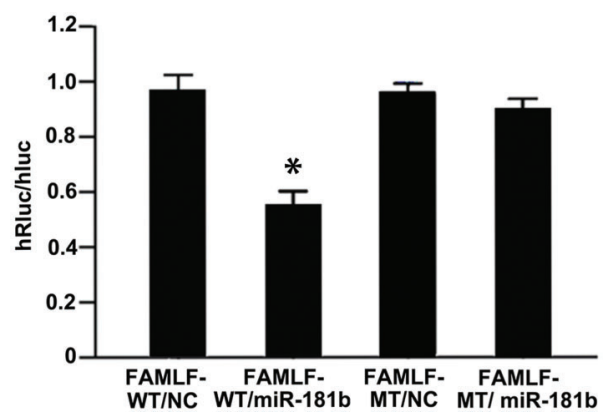

Figure 5. Dual-luciferase reporter gene assay. Renilla luciferase gene activity was reduced by half in 293T cells transfected with miR-181b mimics and the wild-type FAMLF $5^{\prime}$ UTR sequence (FAMLF-WT/miR-181b), while miR-181b negative controls (FAMLF-MT/NC) and the mutated FAMLF $5^{\prime}$ UTR sequence (FMALF-MT/miR-181b) caused no statistical changes in luciferase gene expression. Data are reported as means $\pm S D(n=6)$. ${ }^{*} \mathrm{P}<0.01$, compared to FAMLF-WT/NC, FAMLF-MT/NC and FAMLF-MT/miR-181b (ANOVA). hR/uc: Renilla luciferase reporter gene; hluc: firefly gene.

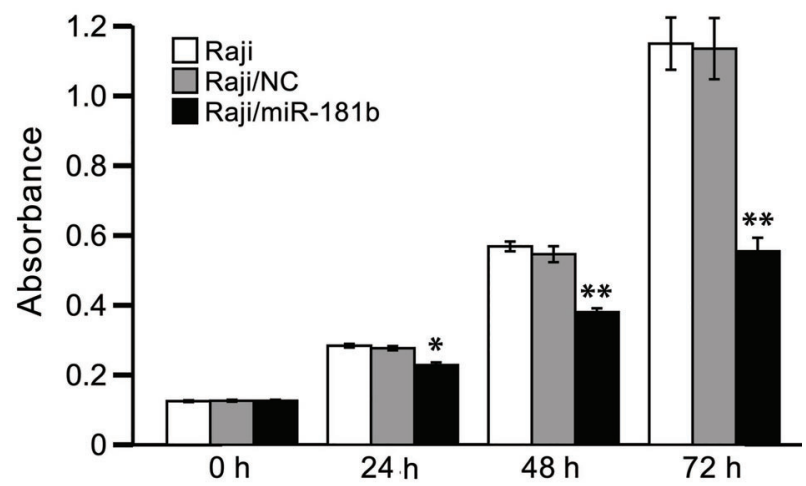

Figure 6. Effect of miR-181b on Raji cell viability. After transfection for 24,48 , and $72 \mathrm{~h}$, cell viability was significantly decreased in the Raji/miR-181b group compared with the Raji and Raji/normalized control (NC) groups, ${ }^{*} \mathrm{P}<0.05$, ${ }^{* *} \mathrm{P}<0.01$ (ANOVA). Data are reported as means $\pm S D(n=6)$. regulate the expression of the host gene (26-28). As FAMLF is the host gene of intronic miR-181b, we postulated that $\mathrm{miR}-181 \mathrm{~b}$ regulated the expression of $F A M L F$. To verify this assumption, RQ-PCR was first performed to detect expression levels of $F A M L F$ and miR-181b in $\mathrm{BL}$ patients with different clinical characteristics. We found that the FAMLF gene was up-regulated in the BL patients with a low expression of miR-181b and down-regulated in the $\mathrm{BL}$ patients with a high expression of miR-181b. FAMLF expression was therefore significantly and inversely correlated to miR-181b expression, indicating a possible negative regulation between intronic miR-181b and the host gene FAMLF. We also found that expression of FAMLF was high in de novo $\mathrm{BL}$ patients and low in the patients in remission, and it was higher in patients with extensive spread than patients with localized lesions, and related to tumor burden. These results showed that the abnormal expression of miR-181b and FAMLF was related to the pathogenesis of $B L$.

miRNA mimics are synthetic miRNAs that can simulate the high expression of endogenous mature miRNA in cells and are simple and efficient tools for studying the regulation of target genes (29). To further verify the role of $\mathrm{miR}-181 \mathrm{~b}$ in the regulation of $F A M L F$, we transfected miR$181 \mathrm{~b}$ mimics into the Raji cell line and then detected the expression of FAMLF. The results showed that after

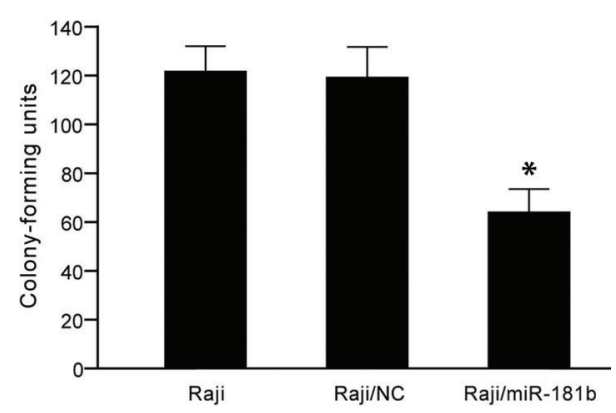

Figure 8. FAMLF down-regulation by miR-181b significantly reduced the colony-formation ability of Raji cells. Colony-forming units were decreased from 119 to 64 after transfection of miR181b. ${ }^{*} \mathrm{P}<0.01$, Raji/miR-181b compared to Raji and Raji/NC (ANOVA). Data are reported as means $\pm S D(n=6)$.

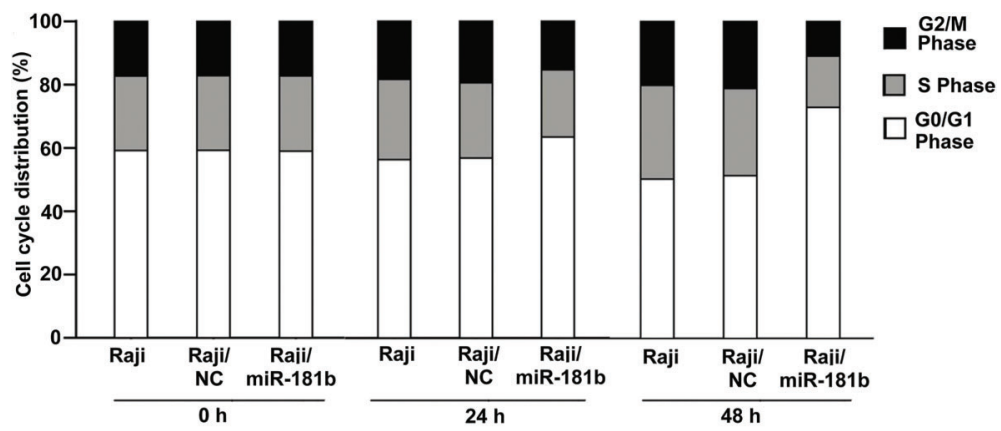

Figure 7. Flow cytometry analysis showing the Raji cell cycle distribution after 24 and $48 \mathrm{~h}$ of transfection. The percentage of cells was increased in G0/G1 phase (58.98-72.94\%) and was reduced in G2/M and S phase after transfection of miR-181b. $\mathrm{P}<0.05$, Raji/miR-181b compared to Raji and Raji/ NC (ANOVA). NC: normalized control. Data are reported as means $(n=6)$. 
A

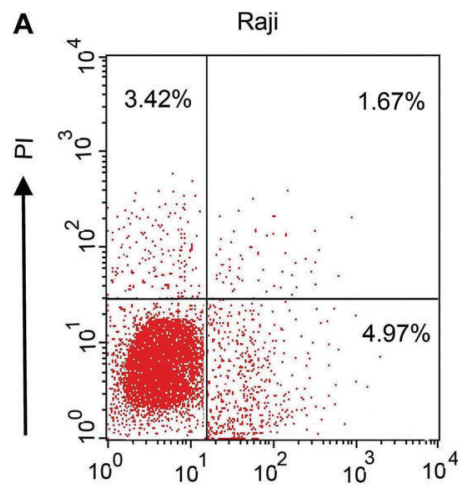

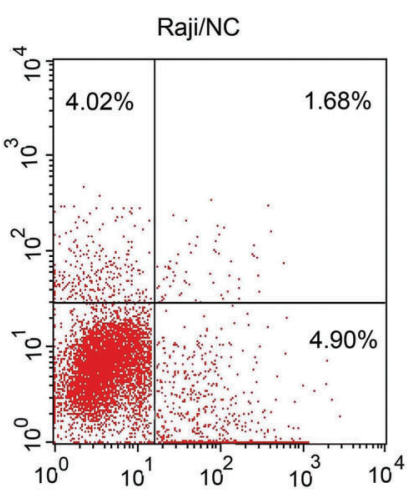

Annexin V FITC

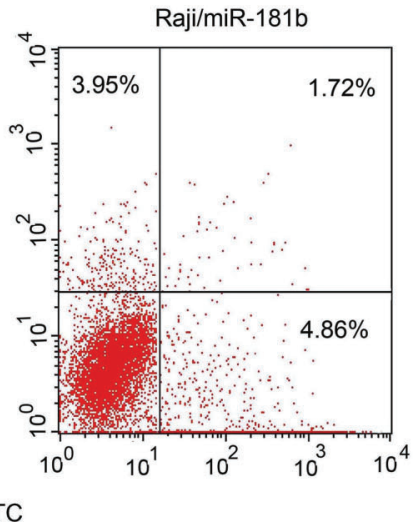

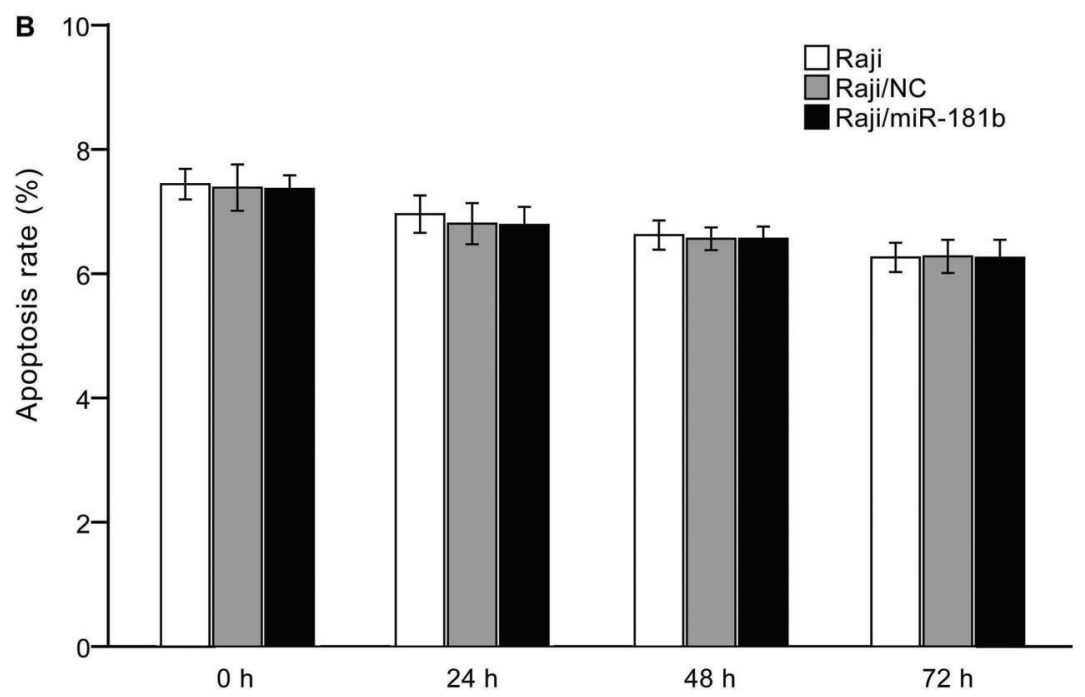

Figure 9. Effect of miR-181b transfection on Raji cell apoptosis. A, Flow cytometry apoptosis scatter diagram after transfection for $48 \mathrm{~h}$. $B$, After transfection for $0,24,48$, and $72 \mathrm{~h}$, total apoptosis rates (early apoptosis and late apoptosis) had no obvious changes in Raji/ miR-181b group compared with control groups (Raji and Raji/NC) $(P>0.05$, ANOVA). Data are reported as means $\pm S D(n=6)$.

transfection of miR-181b mimics, miR-181b expression was increased significantly in the Raji cell line and FAMLF mRNA expression level was decreased by half, while the protein expression level was reduced to $1 / 5$ of control levels. Although some earlier studies reported that miRNA only inhibited expression of target genes at translation level and did not affect the abundance of mRNA in mammals, many subsequent research results indicated that miRNAs can not only inhibit translation of the target mRNA, but also directly induce its degradation by two completely independent mechanisms (30-32). In our experiments, miR-181b down-regulated expression of FAMLF at both the mRNA and translation levels.

Down-regulation of FAMLF by miR-181b could be explained by a direct interaction (miR-181b::FAMLF complementarity) or by an indirect effect. It can be argued that miR-181b interacted with other unknown targets that, in turn, down-regulated the expression of FAMLF. To solve this issue, wild-type and binding site mutation sequences of FAMLF were individually fused into the $5^{\prime}$ UTR of a luciferase reporter gene and were individually cotransfected into 293T cells with miR-181b mimics, and luciferase reporter gene activity was then detected. We found that $h R / u c$ gene activity was significantly reduced in the FAMLF-WT/miR-181b group, but no changes were seen in the control groups. This result indicated a direct effect of miR-181b on FAMLF. Although the traditional mechanism through which miRNAs regulate expression of target genes involves binding to the $3^{\prime}$ UTR of mRNA, increasing number of studies have found that the $5^{\prime}$ UTR and CDS of target genes also contain miRNA binding sites $(33,34)$. miR-181b binding to the $5^{\prime}$ UTR of FAMLF mRNA may inhibit the formation of the mRNA $5^{\prime}$ cap structure to affect the stability of mRNA or may prevent the binding of mRNA 
with the ribosome to inhibit its translation, thus resulting in the down-regulation of FAMLF expression.

A proto-oncogene is a normal gene that helps to regulate cell growth and differentiation and could become an oncogene due to mutation or increased expression (35). Based on our study results in $\mathrm{BL}$, we speculate that FAMLF may play a role similar to that of a proto-oncogene. In this potential mechanism, low expression of mir-181b leads to dysregulation of $F A M L F$, and overexpression of $F A M L F$ may up-regulate expression of genes related to cell proliferation, such as $c-M Y C$, through transcription factor activity, resulting in uncontrolled cell proliferation, which may be an important mechanism of the pathogenesis of BL. In Raji cells transfected with miR-181b, we observed the reduction of cells in S and G2/M phase and inhibition of cell viability and proliferation, demonstrating that the down-regulation of FAMLF by miR-181b is sufficient to inhibit cell viability and proliferation. These

\section{References}

1. Swerdlow SH, Campo E, Harris NL, Jaffe ES, Pileri SA, Stein $\mathrm{H}$, et al. WHO classification of tumors of hematopoietic and lymphoid tissues. 4th edition. Geneva: WHO Press; 2008.

2. Rowe M, Fitzsimmons L, Bell Al. Epstein-Barr virus and Burkitt lymphoma. Chin J Cancer 2014; 33: 609-619.

3. Wang M, Wang SY, Zhang YW, Huang YM, Wang CY, Li JG. Investigation and analysis of a family with acute myeloid leukemia. Chin J Intern Med 2009; 48: 499-501.

4. Zhang YW, Wang SY, Lin X, Wang CY. Identification of differentially expressed genes in familial acute myelogenous leukemia by suppression subtractive hybridization. Zhonghua Yi Xue Za Zhi 2007; 87: 6-10.

5. Li JG, Wang SY, Huang YM, Wang CY. Full-length cDNA cloning and biological function analysis of a novel gene FAMLF related to familial acute myelogenous leukemia. Zhonghua Yi Xue Za Zhi 2008; 88: 2667-2671.

6. Huang YM, Chen LL, Ye ML, Lin SL, Zi YM, Wang SY. Protein expression and subcellular localization of familial acute myelogenous leukemia-related factor. Oncol Rep 2013; 30: 2672-2676.

7. Chen WL, Luo DF, Gao C, Ding Y, Wang SY. The consensus sequence of FAMLF alternative splice variants is overexpressed in undifferentiated hematopoietic cells. Braz $J$ Med Biol Res 2015; 48: 603-609, doi: 10.1590/1414431X20154430.

8. Lee RC, Feinbaum RL, Ambros V. The C. elegans heterochronic gene lin-4 encodes small RNAs with antisense complementarity to lin-14. Cell 1993; 75: 8, doi: 10.1016/ 0092-8674(93)90529-Y.

9. Bartel DP. MicroRNAs: genomics, biogenesis, mechanism, and function. Cell 2004; 116: 281-297, doi: 10.1016/S00928674(04)00045-5.

10. Chen S, Wang Z, Dai X, Pan J, Ge J, Han X, et al. Reexpression of microRNA-50 induces EBV-positive Burkitt lymphoma differentiation by modulating $\mathrm{C}-\mathrm{Myb}$ in vitro. Cancer Sci 2013; 104: 826-834, doi: 10.1111/cas.12156. results indicate that miR-181b may be used for therapy in $\mathrm{BL}$ overexpressing FAMLF.

In conclusion, our study showed that FAMLF expression was inversely correlated to miR-181b expression in $\mathrm{BL}$ and that miR-181b directly down-regulated the expression of FAMLF and inhibited cell viability by binding to the $5^{\prime}$ UTR of FAMLF. Our findings explain a new mechanism of the pathogenesis of $B L$, and miR-181b may be a candidate for therapeutic agents in $B L$ overexpressing FAMLF.

\section{Acknowledgments}

We thank Fujian Institute of Hematology for providing technical instruction and assistance. This study was supported by the National Natural Science Foundation of China (No. 81470008) and Foundation of Education Department in Fujian Province (No. JA11108).

11. Wang M, Yang W, Li M, Li Y. Low expression of miR-150 in pediatric intestinal Burkitt lymphoma. Exp Mol Pathol 2014; 96: 261-266, doi: 10.1016/j.yexmp.2014.02.015.

12. Onnis A, Navari M, Antonicelli G, Morettini F, Mannucci S, De Falco G, et al. Epstein-Barr nuclear antigen 1 induces expression of the cellular microRNA hsa-miR-127 and impairing B-cell differentiation in EBV-infected memory B cells. New insights into the pathogenesis of Burkitt lymphoma. Blood Cancer J 2012; 2: e84, doi: 10.1038/bcj.2012.29.

13. Leucci E, Onnis A, Cocco M, De Falco G, Imperatore F, Giuseppina A, et al. B-cell differentiation in EBV-positive Burkitt lymphoma is impaired at posttranscriptional level by miRNA-altered expression. Int $J$ Cancer 2010; 126: 1316-1326.

14. van Rooij E, Sutherland LB, Qi X, Richardson JA, Hill J, Olson EN. Control of stress-dependent cardiac growth and gene expression by a microRNA. Science 2007; 316: 575-579, doi: 10.1126/science.1139089.

15. Barik S. An intronic microRNA silences genes that are functionally antagonistic to its host gene. Nucleic Acids Res 2008; 36: 5232-5241, doi: 10.1093/nar/gkn513.

16. Radfar $\mathrm{MH}$, Wong $\mathrm{W}$, Morris $\mathrm{O}$. Computational prediction of intronic microRNA targets using host gene expression reveals novel regulatory mechanisms. PLoS One 2011; 6: e19312, doi: 10.1371/journal.pone.0019312.

17. Kos A, Olde Loohuis NF, Wieczorek ML, Glennon JC, Martens GJ, Kolk SM, et al. A potential regulatory role for intronic microRNA-338-3p for its host gene encoding apoptosis-associated tyrosine kinase. PLoS One 2012; 7: e31022, doi: 10.1371/journal.pone.0031022.

18. Chen C, Ridzon DA, Broomer AJ, Zhou Z, Lee DH, Nguyen JT, et al. Real-time quantification of microRNAs by stemloop RT-PCR. Nucleic Acids Res 2005; 33: e179, doi: 10.1093/nar/gni178.

19. Rehmsmeier M, Steffen P, Hochsmann M, Giegerich R. Fast and effective prediction of microRNA/target duplexes. RNA 2004; 10: 1507-1517, doi: 10.1261/rna.5248604. 
20. Chen CZ, Li L, Lodish HF, Bartel DP. MicroRNAs modulate hematopoietic lineage differentiation. Science 2004; 303: 83-86, doi: 10.1126/science.1091903.

21. Li Z, Huang $H$, Li $Y$, Jiang $X$, Chen $P$, Arnovitz $S$, et al. Up-regulation of a HOXA-PBX3 homeobox-gene signature following down- regulation of miR-181 is associated with adverse prognosis in patients with cytogenetically abnormal AML. Blood 2012; 119: 2314-2324, doi: 10.1182/blood-201110-386235.

22. Tong SJ, Liu J, Wang X, Qu LX. microRNA-181 promotes prostate cancer cell proliferation by regulating DAX-1 expression. Exp Ther Med 2014; 8: 1296-1300.

23. Wang F, Sun JY, Zhu YH, Liu NT, Wu YF, Yu F. MicroRNA181 inhibits glioma cell proliferation by targeting cyclin B1. Mol Med Rep 2014; 10: 2160-2164.

24. Pekarsky Y, Santanam U, Cimmino A, Palamarchuk A, Efanov A, Maximov V, et al. Tcl1 expression in chronic lymphocytic leukemia is regulated by miR-29 and miR- 181 . Cancer Res 2006; 66: 11590-11593, doi: 10.1158/00085472.CAN-06-3613.

25. Berezikov E, Guryev V, van de Belt J, Wienholds E, Plasterk RA, Cuppen E. Phylogenetic shadowing and computational identification of human microRNA genes. Cell 2005; 120: 21-24, doi: 10.1016/j.cell.2004.12.031.

26. Berillo $O$, Régnier M, Ivashchenko $A$. Binding of intronic miRNAs to the mRNAs of host genes encoding intronic miRNAs and proteins that participate in tumourigenesis. Comput Biol Med 2013; 43: 1374-1381, doi: 10.1016/ j.compbiomed.2013.07.011.

27. Hinske LC, Galante PA, Limbeck E, Möhnle P, Parmigiani RB, Ohno-Machado L. Alternative polyadenylation allows differential negative feedback of human miRNA miR-579 on its host gene ZFR. PLoS One 2015; 10: e0121507, doi: 10.1371/journal.pone.0121507.

28. Qian J, Tu R, Yuan L, Xie W. Intronic miR-932 targets the coding region of its host gene, Drosophila neuroligin2. Exp Cell Res 2016; 344: 183-193, doi: 10.1016/j.yexcr.2016.01.017.

29. Wang $Z$. The guideline of the design and validation of MiRNA mimics. Methods Mol Biol 2011; 676: 211-223, doi: 10.1007/978-1-60761-863-8.

30. Bagga S, Bracht J, Hunter S, Massirer K, Holtz J, Eachus R, et al. Regulation by let-7 and lin-4 miRNAs results in target mRNA degradation. Cell 2005; 122: 553-563, doi: 10.1016/ j.cell.2005.07.031

31. Wu L, Fan J, Belasco JG. MicroRNAs direct rapid deadnylation of mRNA. Proc Natl Acad Sci USA 2006; 103: 4034-4039, doi: 10.1073/pnas.0510928103.

32. Eulalio $A$, Huntzinger $E$, Izaurralde $E$. Getting to the root of miRNA-mediated gene silencing. Cell 2008; 132: 9-14, doi: 10.1016/j.cell.2007.12.024.

33. Tay Y, Zhang J, Thomson AM, Lim B, Rigoutsos I. MicroRNAs to Nanog, Oct4 and Sox2 coding regions modulate embryonic stem cell differentiation. Nature 2008; 455: 1124-1128, doi: 10.1038/nature07299.

34. Helwak A, Kudla G, Dudnakova T, Tollervey D. Mapping the human miRNA interactome by CLASH reveals frequent noncanonical binding. Cell 2013; 153: 654-665, doi: 10.1016/ j.cell.2013.03.043

35. Hoffman B, Amanullah A, Shafarenko M, Liebermann DA. The proto- oncogene c-myc in hematopoietic development and leukemogenesis. Oncogene 2002; 21: 3414-3421, doi: 10.1038/sj.onc. 1205400 . 